\title{
HIV infection and Mycoplasma co-infection: case- control study in a female population of Douala (Cameroon)
}

\begin{abstract}
Objective: To determine the impact of Human Immuno-Deficiency Virus (HIV) on coinfection with Mycoplasma hominis and Ureaplasma urealyticum in HIV-infected women.

Methodology: A case-control analytical study based on standardized questionnaire interview and cervical sample collection after informed consent obtained among HIVpositive and HIV-negative women from January $2^{\text {nd }}, 2017$ to June $30^{\text {th }}, 2017$ received at the laboratory of Laquintinie Hospital in Douala. Samples collected were used for mycoplasma research, quantification, and antibiogram using the mycoplasma IES kits. Sociodemographic, clinical and biological variables of interest were entered and analyzed on Microsoft Office Excel 2013 and Statistical Package for Social Sciences (SSPS) software version 20 and the chi-square correlation test was used with significance at the threshold of $\mathrm{P}<5 \%$.
\end{abstract}

Results: We analysed 136 samples of women aged 18-65years, among which $96 \mathrm{HIV}+($ cases $)$ matched with $40 \mathrm{HIV}$-(controls). The mean age of the case group was $39.08 \pm 10.22$ years and that of the control group was $33.28 \pm 8.68$ years. Genital mycoplasmas were found in $58.3 \%$ of cases, with a high frequency for $U$. urealyticum $(19.8 \%)$ against $2.1 \%$ for $M$. hominis and the two germs were associated in $32.3 \%$ of cases. In the control group, the carrier rate was $62.5 \%$, with a frequency of $17.5 \%$ for Ureaplasma alone and no carrier for $M$. hominis alone. Co-infection with the two germs in this group was $40 \%$. The majority of HIV+women had a CD4 count above 200, and no significant association was found between CD4 count and the presence of mycoplasma in these women $(\mathrm{P}=0.094)$

Conclusion: Mycoplasma infection is common in HIV+ women. However, there is no significant association between the CD4 count and the presence of these mycoplasmas.
Volume II Issue 2 - 2020

\author{
Essome Henri, ${ }^{1,2}$ Nida Martine Colette,' \\ Mve Koh Valère, ${ }^{3}$ Ekono Michel Roger, ${ }^{\prime}$ \\ Nana Njamen Théophile, ${ }^{4}$ Boten Merlin, ${ }^{2}$ \\ Tocki Toutou Grâce, ${ }^{2}$ Halle Ekane Gregory, ${ }^{4}$ \\ Adiogo Dieudonné \\ 'Faculty of Medicine and Pharmaceutical Sciences of Douala, \\ University of Douala, Cameroon \\ 2Laquintinie Hospital, Cameroon \\ ${ }^{3}$ Faculty of Medicine and Biomedical Sciences of Yaoundé, \\ University of Yaounde I, Cameroon \\ ${ }^{4}$ Faculty of Health Sciences of Buea, University of Buea, \\ Cameroon
}

Correspondence: Essome Henri, Faculty of Medicine and Pharmaceutical Sciences of Douala, University of Douala, Laquintinie Hospital, Cameroon, Tel +237696475672 . Emailessometock@yahoo.com

Received: February 14, 2020 | Published: March 09, 2020

Keywords: CD4, HIV, mycoplasma hominis, ureaplasma urealyticum

Abbreviations: HIV, human immuno-deficiency virus; SSPS, statistical package for social sciences; STIs, sexually transmitted infections; AIDS, acquired immune deficiency syndrome; DHS, demographic and health survey; MH, Mycoplasma hominis; UU, Ureaplasma urealyticum

\section{Introduction}

Infection with the human immunodeficiency virus (HIV) is still current in all countries of the world, with 37.9 million people living with HIV, 2.3 million new people infected in 2018 and responsible for 770,000 deaths in 2018.1 The high prevalence of sexually transmitted infections (STIs) and HIV/acquired immune deficiency syndrome (AIDS) are a real public health problem in many developing countries. It represents approximately $10 \%$ of the reasons for consultations in the sexually active population. According to the results of the DHS (Demographic and Health Survey) III 2004, women are more exposed, that is $7.9 \%$ of women carrying the virus against $2.5 \%$ in men. ${ }^{2}$ Most of these STIs are treated and cured if the diagnosis is made. If left untreated, they can have real complications such as infertility, premature rupture of membranes, neonatal infections, hepatitis or cancer of the cervix; some can be prevented by vaccination such as hepatitis B, the papillomavirus. All these STIs, especially ulcers, weaken the mucosa and increase the risk of HIV transmission. Interest has therefore been paid to these STIs, including: Mycoplasma hominis $(\mathrm{MH})$ and Ureaplasma urealyticum (UU) infections.
Many studies on this co-infection have been carried out in certain countries, notably in Italy with a prevalence of $41 \%$ for UU and $11 \%$ for $\mathrm{MH},{ }^{3} 7.5 \%$ in Burkina Faso, ${ }^{4} 19.3 \%$ in the Central African Republic, ${ }^{5}$ a prevalence of $20 \%$ among women in Cameroon. ${ }^{6}$ These two bacteria are frequently part of the "normal vaginal" flora. This porterage is therefore in most cases safe for human health. Mycoplasma hominis and Ureaplasma urealyticum are more commonly isolated from adults than children, from pregnant women than from non-pregnant women, and may be more at risk in HIV positive people than in HIV negative people. The presence of these germs in HIV-positive women of reproductive age could therefore complicate their already fragile state of health.

The low availability of information on the link between mycoplasma infection and increased risk of pathogenesis in HIV positive subjects motivated us to conduct this study at the Laquintinie hospital in Douala.

\section{Patients, materials and methods}

a. Type of study: It was a prospective analytical case-control study

b. Period and duration of the study: Our study took place from January $02^{\text {nd }} 2017$ to June $30^{\text {th }}, 2017$. A duration of six months

c. Study population, inclusion and exclusion criteria: Our study population consisted of both positive and negative HIV patients seen at the clinical biology laboratory at Laquintinie Hospital 
during this period. Included were those who were consenting after clarified information, while those who were menstruating or under active antibiotic therapy on mycoplasmas were excluded.

d. Sampling: The sampling was consecutive with a minimum size (N) determined at 106 according to the Lorentz formula $(\mathrm{N})$.

$\mathrm{N}=\mathrm{P}(1-\mathrm{P})(\mathrm{Z} 2 \alpha / \alpha 2) \mathrm{P}=7.5 \%$ (prevalence of co-infection of $M$. hominis and U. urealyticum in HIV positive subjects $=0.075)^{4}$

Where,

$\mathrm{Z} \alpha: 1.96$

$\alpha$ : relative risk $5 \%(0.05)$

$N \approx 106$ Subjects for cases; the size of the control population was defined by convenience as $1 / 3$ of the cases

\section{Materials and methods}

\section{Data collection}

After addressing and explaining to patients the different information on the research topic, the data was obtained from a pretested survey sheet and the CD4 count was recorded confidentially in the HIV+patient book.

Variables studied: The variables of interest were socio-demographic (age, marital status, level of education, type of occupation) clinical (number of sexual partners, use of condoms, history of STI) and biological (HIV typing), mycoplasma, CD4 count).

\section{Pre-analytical phase}

i. Screening of controls: Screening of controls (HIV-negative group) was systematically done using the Determine Alere HIV$1 / 2$.

ii. Sample collection: After having comfortably received and installed the patient in a gynecological position, we checked the conformity of the sampling equipment (conforming identification). Next, we exposed the cervix using the speculum and collected from the endocervix with a swab.

\section{Analytical phase}

Principle of the test: The "MYCOPLASMA IES" kit allows research, semi-quantitative counting, presumptive identification and antibiogram of $M$. hominis and $U$. urealyticum isolated by clinical samples. The kit is a system of 30 wells containing biochemical substrates and dried antibiotics. The principle of this test is to detect the metabolic activity of urogenital mycoplasmas on a selective medium supplemented with antibiotics, to assess resistance or sensitivity to antibiotics.
After culturing the mycoplasmas, the urea can be broken down by the urease, releasing $\mathrm{NH} 3$ in the case of $U$. urealyticum; arginine can be broken down by arginase, also releasing NH3 in the case of $M$. hominis. The NH3 released increases the $\mathrm{pH}$ of the medium and the result is obtained by observing the change in color. Antibiotic sensitivity is revealed when there is no change in color due to the inhibition of enzyme activity.

\section{Sample preparation}

We first brought the reagents to room temperature, then we added the diluent to the dehydrated medium. The swab used for the sample was immersed in the mixture. We carefully pressed the swab against the wall of the vial, so that the material was evenly dispersed in the physiological solution. A suspension was thus obtained.

Inoculation of the system after bringing the galleries to room temperature $\left(18-25^{\circ} \mathrm{C}\right)$, we noted the patient identification number and the date of the start of the examination. We then transferred $100 \mu 1$ of the sample suspension to each well in the gallery and covered all the wells with a drop of paraffin oil. We finally covered the gallery with a cover provided for this purpose and incubated the gallery at $37.5^{\circ} \mathrm{C}$ for 24 hours.

\section{Post-analytical phase}

The pathogenicity threshold for a urogenital infection is fixed at $105 \mathrm{UCC} / \mathrm{ml}$, which makes it possible to define a colonization for a value $<104 \mathrm{UCC} / \mathrm{ml}$ and an infection for a value $\geq 104 \mathrm{UCC} / \mathrm{ml}$.

\section{Results interpretation}

The results are obtained after a change in color. If the color changes from yellow to red, it implies the growth of mycoplasmas and if the color does not change, it can mean negative growth or sensitivity to antibiotics. Rarely, the color may be pink, and, in this case, the incubation time should be extended from 12 to 24 hours. The strain is sensitive when it is inhibited by the two concentrations of the antibiotic, intermediate when it is inhibited by the large concentration and not the small, resistant when it is not inhibited by either of the two concentrations (Figure 1).

A. Culture and identification are observed in wells no. 1, 2, 5; well no. 5 for the positive control, well no. 1 for identification of $U$. urealyticum, well no. 2 for the identification of M. hominis,

B. The enumeration is observed in wells no. $3\left(\mathrm{UU} \geq 10^{4}\right)$ for the enumeration of $U$. Urealyticum and well no. $4\left(\mathrm{MH} \geq 10^{4}\right)$ for the enumeration of M. hominis,

C. Antibiotic sensitivity tests are observed in wells 6 to 30 .

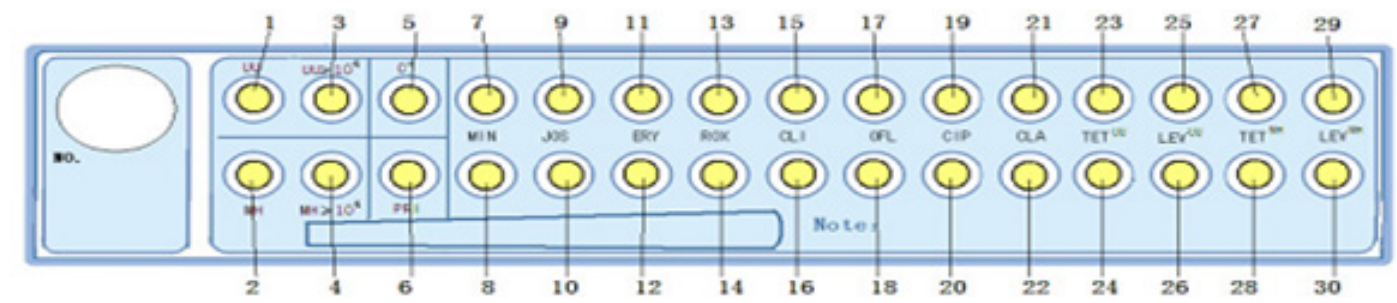

Figure I mycoplasma gallery. 


\section{Statistical analyzes}

Statistical analyzes were performed with Statistical Package for Social Sciences (SSPS) version 20 and Microsoft Office Excel 2013. The chi-square correlation test was used at the significance level of $\mathrm{P}<0.05$

\section{Ethical criteria}

We obtained the agreement of the institutional ethics committee of the FMSP (Faculty of Medicine and Pharmaceutical Sciences) of the University of Douala for the realization of this study.

\section{Results}

During our study period, we identified 106 HIV positive women constituting the case group, matched to $40 \mathrm{HIV}$ negative women constituting the control group and 10 women were excluded in HIV positive patients $(03$ not meeting the inclusion criteria and 07 who refused to give consent) Figure 2.

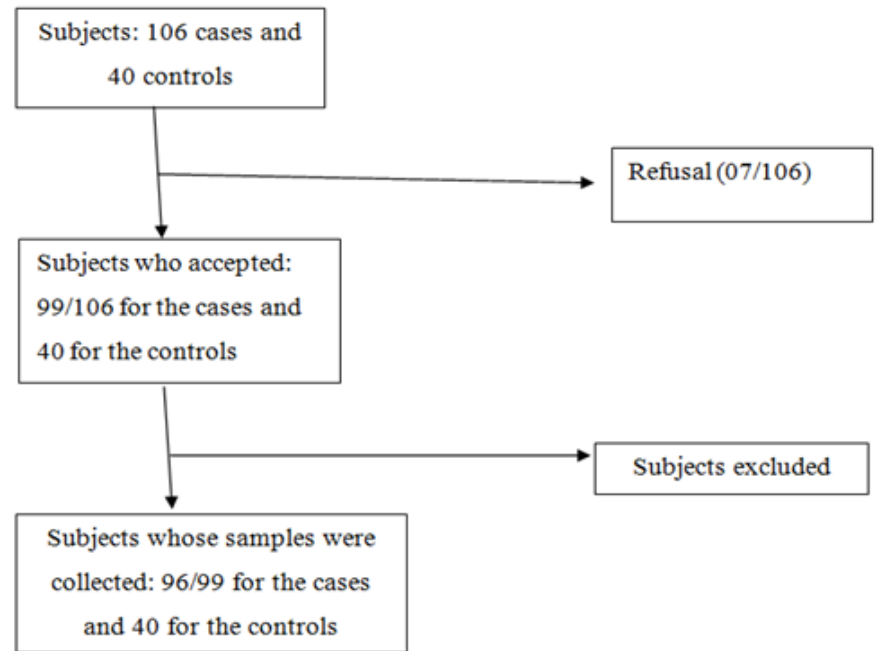

Figure 2 Diagram of participation in the study.

\section{Socio demographic data}

The mean age was $39.08 \pm 10.22$ in cases compared to $33.28 \pm$ 8.68 in controls. The majority age group was that of 38-48 among HIV-positive people: $47 \%(\mathrm{~N}=40)$ and $28-38$ among controls: $45 \%$ $(\mathrm{N}=18)$.

The majority level of study was primary in HIV-positive people: $48.8 \%(\mathrm{~N}=42)$ and secondary in controls: $52.5 \%(\mathrm{~N}=21)$. Our respondents were mainly single $(50 \%$ and $65 \%)$ and housewives $(45.8 \%$ and $47.5 \%)$ in the two groups with twice as many widows among HIV-positive people than among controls (Table 1).

\section{Clinical data}

Type 1 HIV was found in $95.8 \%$ of HIV-positive women (N=92) (Table 2).

Most of our respondents declared having only one sexual partner in the two groups with a respective percentage of $60.4 \%$ among HIVpositive people $(\mathrm{N}=58)$ and $65 \%(\mathrm{~N}=26)$ among controls. On the other hand, $10.4 \%$ of HIV+women declared having more than one partner compared to $0 \%$ among the controls.
Table I Socio-demographic characteristics

\begin{tabular}{llll}
\hline & HIV + & HIV - & \\
Variables & N=96 & N=40 & P. value \\
& n (\%) & n (\%) &
\end{tabular}

\begin{tabular}{|c|c|c|c|}
\hline \multicolumn{4}{|l|}{ Age } \\
\hline Mean $\pm S D$ & $39.08 \pm 10.22$ & $33.28 \pm 8.68$ & 0.002 \\
\hline \multicolumn{4}{|l|}{ Range } \\
\hline [18-28] & $14(14.6)$ & II (27.5) & \multirow{4}{*}{0.006} \\
\hline [28-38] & $24(25.0)$ & $18(45.0)$ & \\
\hline [38-48] & 40 (4I.7) & $8(20.0)$ & \\
\hline$\geq 48$ & $18(18.8)$ & $3(7.5)$ & \\
\hline \multicolumn{4}{|c|}{ Educational level } \\
\hline None & $3(3.1)$ & $0(0.0)$ & \multirow{4}{*}{0} \\
\hline Primary & $42(43.8)$ & $10(25.0)$ & \\
\hline Secondary & $40(41.7)$ & $21(52.5)$ & \\
\hline High level & II (I I.5) & $9(22.5)$ & \\
\hline \multicolumn{4}{|c|}{ Marital status } \\
\hline Married & $30(3 \mid .2)$ & II (27.5) & \multirow{4}{*}{0.251} \\
\hline Single & $48(50.0)$ & $26(65.0)$ & \\
\hline Divorced & $4(4.0)$ & $0(0)$ & \\
\hline Widow & I4 (I4.6) & $3(7.5)$ & \\
\hline \multicolumn{4}{|l|}{ Occupation } \\
\hline Housewife & $44(45.8)$ & 19 (47.5) & \\
\hline Teacher & $8(8.3)$ & $2(5.0)$ & \\
\hline Student & II (II.5) & II (27.5) & \\
\hline Trader & $12(12.5)$ & $6(15.0)$ & 0.264 \\
\hline Nurse & $2(2.1)$ & $2(5.0)$ & \\
\hline Hairdresser & $14(14.6)$ & $0(0)$ & \\
\hline Restaurateur & $5(5.2)$ & $0(0)$ & \\
\hline
\end{tabular}

Table 2 Distribution of HIV positive women with respect to type of HIV

\begin{tabular}{lll}
\hline Type of HIV & Frequency & Parentage (\%) \\
\hline HIV I & 92 & 95.8 \\
HIV 2 & 4 & 4.2 \\
Total & 96 & 100 \\
\hline
\end{tabular}

Regarding the use of condoms, $56.2 \%$ of HIV-positive women did not systematically use condoms compared to $37.5 \%$ among controls. In contrast, the group infected with HIV had less history of STIs $(39.6 \%)$ than the control group $(67.5 \%)$ (Table 3$)$. 
Table 3 Distribution of population with respect to behavioural risks and history of STls

\begin{tabular}{|c|c|c|c|}
\hline Variables & $\begin{array}{l}\text { HIV + } \\
N=96 \\
n(\%)\end{array}$ & $\begin{array}{l}\text { HIV - } \\
N=40 \\
n(\%)\end{array}$ & P. value \\
\hline \multicolumn{4}{|c|}{ Number of partners } \\
\hline None & $26(27.1)$ & $14(35.0)$ & \\
\hline One & $58(60.4)$ & $26(65.0)$ & \\
\hline Two & $2(2.1)$ & $0(0.0)$ & \\
\hline Many & $10(10.4)$ & $0(0.0)$ & 0 \\
\hline \multicolumn{4}{|c|}{ Use of condom } \\
\hline Yes & $32(33.3)$ & $18(45.0)$ & \\
\hline No & $54(56.2)$ & $15(37.5)$ & \\
\hline Sometimes & $10(10.4)$ & $7(17.5)$ & 0.126 \\
\hline
\end{tabular}

\begin{tabular}{llll}
\hline & HIV + & HIV - & \\
Variables & $\mathbf{N}=96$ & $\mathbf{N}=40$ & P. value \\
& $\mathbf{n}(\%)$ & $\mathbf{n}(\%)$ & \\
\hline History of STIs & & \\
Chlamydia & $14(14.6)$ & $7(17.5)$ & 0.668 \\
Syphilis & $16(16.7)$ & $7(17.5)$ & 0.906 \\
Others* & $8(8.3)$ & $13(32.5)$ & 0 \\
\hline
\end{tabular}

*: infections with trichomonas, gardnerella vaginalis, and candida vaginalis

\section{Biological data}

The prevalence of mycoplasma carriage was higher in the controls $(62.5 \%)$ than in the seropositive $(58.3 \%)$ with, however, a nonsignificant statistical difference $(\mathrm{P}=0,652)$ (Table 4).

However, peak frequency of carriage and infection were observed in the age group 18-28 in both groups and HIV+women in this age group were all infected with a mycoplasma. The co-infection rate was $32.3 \%$ in cases (HIV+women) and $40 \%$ in controls (Table 5).

Table 4 Prevalence of mycoplasma in the study population

\begin{tabular}{lllll}
\hline & HIV + & HIV - & & \\
& $\mathbf{N = 9 6}$ & $\mathbf{N = 4 0}$ & OR (CI : 95\%) & P. value \\
& $\mathbf{n}(\%)$ & $\mathbf{n}(\%)$ & & \\
\hline Absence & $40(41.7)$ & $15(37.5)$ & $1.19(0.56-2.54)$ & 0.652 \\
Total carriage & $56(58.3)$ & $25(62.5)$ & $0.84(0.39-1.79)$ & 0.652 \\
Colonisation & $4(4.2)$ & $2(5.0)$ & $0.83(0.15-4.70)$ & 1 \\
Infection with M. hominis & $2(2.1)$ & $0(0.0)$ & - & - \\
Infection with U urealyticum & $19(19.8)$ & $7(17.5)$ & $1.16(0.45-3.03)$ & 0.757 \\
Co-infection & $31(32.3)$ & $16(40.0)$ & $0.72(0.33-1.54)$ & 0.389 \\
\hline
\end{tabular}

Table 5 Distribution of prevalence rate of mycoplasma in the population according to age

\begin{tabular}{|c|c|c|c|c|c|}
\hline & $\begin{array}{l}\text { [18-28] } \\
\text { n (\%) }\end{array}$ & $\begin{array}{l}\text { [28-38] } \\
\text { n (\%) }\end{array}$ & $\begin{array}{l}\text { [38-48] } \\
\text { n (\%) }\end{array}$ & $\begin{array}{l}\geq 48 \\
\text { n (\%) }\end{array}$ & $\begin{array}{l}\text { Total } \\
\text { n (\%) }\end{array}$ \\
\hline $\mathrm{HIV+}$ & $N=14$ & $N=24$ & $N=40$ & $N=18$ & $N=96$ \\
\hline Absence & $0(0.0)$ & $12(50.0)$ & $20(50.0)$ & $8(44.4)$ & $40(4 I .7)$ \\
\hline Colonisation & $0(0.0)$ & $0(0.0)$ & $4(10.0)$ & $0(0.0)$ & $4(4.2)$ \\
\hline Infection with $\mathrm{M}$. hominis & $0(0,0)$ & $0(0,0)$ & $2(5,0)$ & $0(0,0)$ & $2(2, I)$ \\
\hline Infection with $U$. urealyticum & $4(28.6)$ & $6(25.0)$ & $3(7.5)$ & $6(33.3)$ & $19(19.8)$ \\
\hline Co-infection & $10(7 \mid .4)$ & $6(25.0)$ & II (27.5) & $4(22.2)$ & $31(32.3)$ \\
\hline Sub-total carriage & $14(100.0)$ & $12(50.0)$ & $20(50.0)$ & $10(55.5)$ & $56(58.3)$ \\
\hline Sub-total infected women & $14(100.0)$ & $12(50.0)$ & $16(40.0)$ & $10(55.5)$ & $52(54.1)$ \\
\hline HIV- & $N=11$ & $N=18$ & $N=8$ & $N=3$ & $N=40$ \\
\hline Absence & I (9.1) & $8(44.4)$ & $5(62.5)$ & I (33.3) & $15(37.5)$ \\
\hline Colonisation & I (9.1) & I (5.6) & $0(0.0)$ & $0(0.0)$ & $2(5.0)$ \\
\hline Infection with M. hominis & $0(0.0)$ & $0(0.0)$ & $0(0.0)$ & $0(0.0)$ & $0(0.0)$ \\
\hline Infection with U. urealyticum & $3(27.3)$ & $3(16.7)$ & $I(12.5)$ & $0(0.0)$ & $7(17.5)$ \\
\hline Co-infection & $6(54.5)$ & $6(33.3)$ & $2(25.0)$ & $2(66.7)$ & $16(40.0)$ \\
\hline Sub-total carriage & $10(91.0)$ & $10(55.5)$ & $3(37.5)$ & $2(66.7)$ & $25(62.5)$ \\
\hline Sub-total infected women & $9(81.8)$ & $9(50.0)$ & $3(37.5)$ & $2(66.7)$ & $23(57.5)$ \\
\hline
\end{tabular}


In the search for a possible correlation between the carriage of mycoplasmas and certain socio-demographic parameters in the two groups, it appeared that the prevalence of carriage of mycoplasmas was higher among housewives and single people of the two groups and women of primary educational level were more infected in HIV positive patients: $44.6 \%$ (versus $20 \%$ in controls) (Table 6 ).

Table 6 Distribution of prevalence rate of mycoplasma carriers with respect to marital status, type of occupation and level of education

\begin{tabular}{|c|c|c|c|c|}
\hline \multirow{4}{*}{ Status } & \multicolumn{2}{|l|}{ HIV+ } & \multicolumn{2}{|l|}{ HIV- } \\
\hline & Presence & Absence & Presence & Absence \\
\hline & $N=56$ & $N=40$ & $N=25$ & $N=\mid 5$ \\
\hline & $n(\%)$ & $n(\%)$ & $n(\%)$ & $n(\%)$ \\
\hline \multicolumn{5}{|c|}{ Type of occupation } \\
\hline Housewife & $28(50.0)$ & $16(40.4)$ & II (44.0) & $8(53.3)$ \\
\hline Teacher & $2(3.6)$ & $6(15.0)$ & $2(8.0)$ & $0(0)$ \\
\hline Student & II (19.6) & $0(0.0)$ & $9(36.0)$ & $3(20.0)$ \\
\hline Trader & $4(7.1)$ & $8(20.0)$ & $2(8.0)$ & $3(20.0)$ \\
\hline Nurse & $2(3.6)$ & $0(0)$ & I (4.0) & I (6.7) \\
\hline Hairdresser & $4(7.1)$ & $10(25.0)$ & $0(0)$ & $0(0)$ \\
\hline Restaurateur & $5(8.9)$ & $0(0.0)$ & $0(0)$ & $0(0)$ \\
\hline \multicolumn{5}{|c|}{ Marital status } \\
\hline Married & $14(25.0)$ & $16(40.0)$ & $4(16.0)$ & 7 (46.7) \\
\hline Single & $32(57.1)$ & $16(40.0)$ & $20(80.0)$ & $6(40.0)$ \\
\hline Divorced & $2(3.6)$ & $2(5.0)$ & I (4.0) & $2(13.3)$ \\
\hline Widow & $8(14.3)$ & $6(15.0)$ & $0(0)$ & $0(0)$ \\
\hline \multicolumn{5}{|c|}{ Level of education } \\
\hline None & I (I.8) & $2(5.0)$ & $0(0)$ & $0(0)$ \\
\hline Primary & $25(44.6)$ & I8 (45.0) & $5(20.0)$ & $5(33.3)$ \\
\hline Secondary & $22(39.3)$ & $17(42.5)$ & $14(56.0)$ & $7(46.7)$ \\
\hline High level & $8(14.3)$ & $3(7.5)$ & $6(24.0)$ & $3(20.0)$ \\
\hline
\end{tabular}

Ureaplasma urealyticum had a high sensitivity to macrolides (Figure 3) and josamycin presented a better sensitivity in co-infection situation (Figure 4). All the HIV+subjects in our study with less than 200 CD4 were carriers of Ureaplasma uréalyticum (i.e. 100\%).
In subjects with a CD4 count $>200,55.4 \%$ had a mycoplasma. However, the chi-square correlation test $(\mathrm{P}=0.094)$ was not significant. So, the carriage of mycoplasmas was not influenced by the immune state (Table 7).

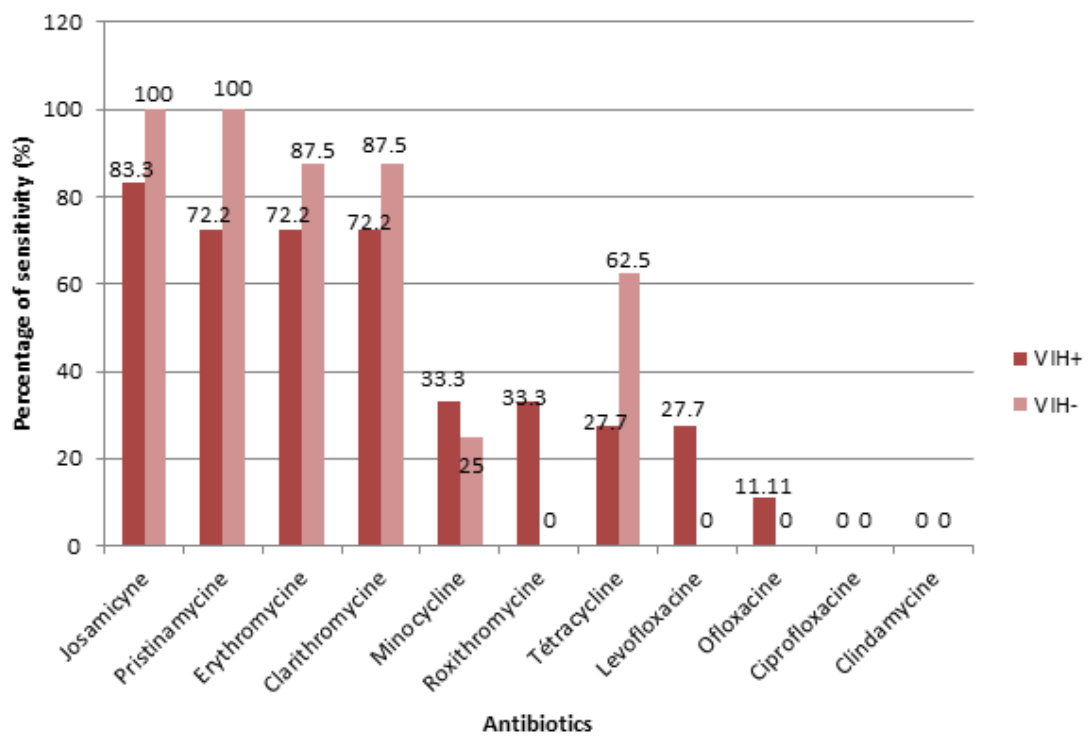

Figure 3 Sensitivity profile of Ureaplasma urealyticum.

Citation: Henri E, Colette NM,Valère MK, et al. HIV infection and Mycoplasma co-infection: case-control study in a female population of Douala (Cameroon). Obstet Gynecol Int J. 2020; I (2):93-99. DOI: 10.15406/ogij.2020.1 I.00494 


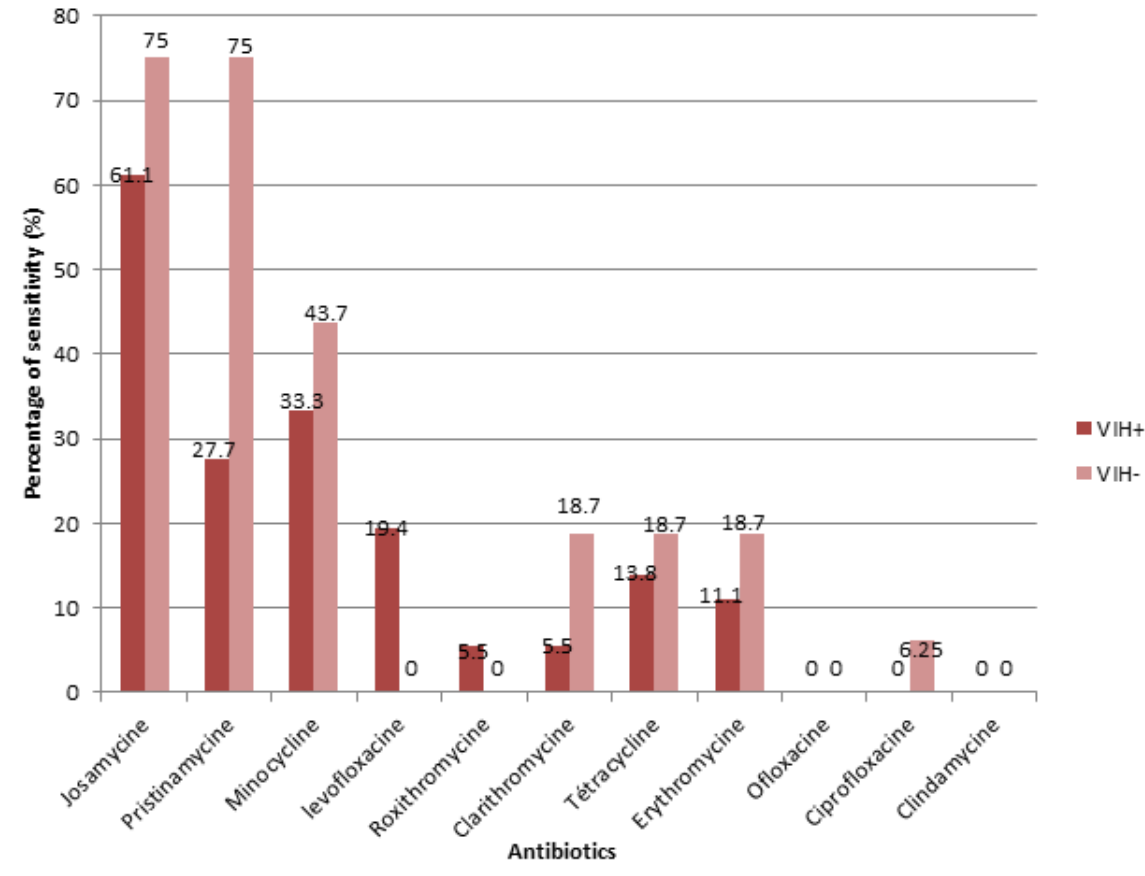

Figure 4 Sensitivity profile of Mycoplasma hominis associated with Ureaplasma urealyticum.

Table 7 Comparison of CD4 count with germs detected

\begin{tabular}{lllll}
\hline CD4 count & $\mathbf{N}=96$ & $\begin{array}{l}\text { Mycoplasma hominis } \\
\mathbf{n}(\%)\end{array}$ & $\begin{array}{l}\text { Ureaplasma urealyticum } \\
\mathbf{n}(\%)\end{array}$ & $\begin{array}{l}\text { M. hominis et U. urealyticum } \\
\mathbf{n}(\%)\end{array}$ \\
\hline$\leq 200$ & 6 & $0(0.00)$ & $I(16.7)$ & $5(83.3)$ \\
200 and above & 90 & $2(2.2)$ & $17(18.8)$ & $31(34.4)$ \\
\hline
\end{tabular}

\section{Discussion}

We discussed our results with those of works from the same geographical area and elsewhere

Limits: The declarative nature of the socio-demographic, clinical data and the size of our sample constituted its limits.

\section{Sociodemographic characteristics}

The age: The age extremes of our total sample were 18 and 65 with averages of $39.08 \pm 10.22$ years in HIV positive women and $33.28 \pm 8.68$ years in HIV negative women. So, we had a sample of women, mostly of reproductive age. Our results approximate the 37 years of Mbamba, ${ }^{6}$ and the $34.02 \pm 6.51$ years of Djigma ${ }^{4}$ whose extremes were from 20 to 53 years.

\section{Type of occupation, marital status and level of study}

Housewives and singles were in the majority in our two matched groups. They had primary education level $(41.7 \%)$ for HIV positive and secondary education (52.5\%) for controls. Our results confirm those of the work of Djigma ${ }^{4}$ and Mbamba. ${ }^{6}$

\section{Prevalence of mycoplasmas}

The rate of mycoplasma carriage was $58.3 \%$ in HIV-positive women and $62.5 \%$ in HIV-negative women. The data in the literature vary widely depending on the place of study, with prevalence varying from 20 to $92 \%$. Rapelanoro et $a .^{5}$ report $92 \%$ of mycoplasma carriage rates in HIV-positive women of reproductive age in Bangui; Faye-kette et al. ${ }^{7}$ in Ivory Coast report carryings of $22 \%$ for $U$. uréalyticum and $20 \%$ for $M$. hominis; $30.9 \%$ carriage of $M$. hominis found by Mamadou et al. ${ }^{8}$ in a group of sex workers in Niamey and $71.4 \%$ carriage of mycoplasma in Mbamba et $a .^{6}{ }^{6}$ in Cameroon in a study carried out on $84 \mathrm{HIV}$ positive women. In our study, we did not observe any statistical difference with respect to HIV status.

The group of 18-28 years old is recognized sexually very active and carefree about STI prevention concerns; this is demonstrated by the high prevalence of mycoplasma infections found in this group in the two groups in our sample, as well as the high rate of risky sexual behavior exhibited by most of these women. All HIV positive women in this age group were infected with $U$. urealyticum.

\section{Sensitivity profile}

Macrolides are usually very active on mycoplasmas; evidenced by the high sensitivity of Ureaplasma urealyticum and Mycoplasma hominis to josamycin and pristinamycin found in our study. Our findings agree with data from the literature and the work of $\mathrm{Mbamba}^{6}$ whose strains of mycoplasmas had a sensitivity of $100 \%$ to josamycin and pristinamycin.

\section{Correlation of mycoplasmas with the level of immunity}

In our study, there was no causal link between CD4 count and mycoplasma infection. The data in the literature are mixed on this subject. 
As much as our findings confirm those of Lanzafame ${ }^{3}$ and Djigma ${ }^{4}$ they contradict those of Levine ${ }^{9}$ whose work reports a strong association between CD4 count and mycoplasma infection. But this discrepancy in the data is to be credited to the small size of our sample, opposed to its own, but also to its mode of recruitment, which specifically included cases of vaginosis or risky sexual contact with an infected partner. The follow-up and the quality of improved care for HIV-positive women also seem to us to be an argument in favor of this lack of link between CD4 count and mycoplasma infection. ${ }^{10-20}$

\section{Conclusion}

Most HIV-positive women in our sample were infected with mycoplasmas, but without statistical significance between the two groups regarding HIV status. Most HIV positive women had a CD4 count greater than 200. Furthermore, there was no correlation between mycoplasma infection and CD4 count.

\section{Acknowledgments}

The authors thank the authorities of Laquintinie Hospital and the personnel of the laboratory of Laquintinie Hospital for the administrative support as well as all the facilities granted to them during this study.

\section{Funding}

None.

\section{Author contribution}

Essome designed the study, collected the data and wrote the manuscript; Nida, Mve, Ekono, Nana, Boten, Tocki have read and corrected the manuscript; Halle and Adiogo supervised the study, corrected and validated the final version of the manuscript.

\section{Conflicts of interest}

The authors declare on their honor that they have no conflict of interest.

\section{References}

1. UNAIDS 2018 Fact sheet. World statistics. 2018.

2. Cameroon: Why the HIV / AIDS epidemic is not declining in Cameroon - all Africa. 2018

3. Lanzafame M, Delama A, Lattuada E, et al. Prevalence and clinical significance of Ureaplasma urealyticum and Mycoplasma hominis in the lower genital tract of HIV-1-infected women. Infez Med. 2006;14:213215.

4. Djigma WF. Co-infection of mycoplasma homnis and ureaplasma urealyticum with the human immunodeficiency virus in HIV-positive women in Ouagadougou. Doctoral thesis in medicine. Burkina faso: university of ouagadougou, 2009. $67 \mathrm{p}$.
5. Rapelanoro RF, Lepere P, Escarguel C, et al. Prevalence of urogenital mycoplasma infection in women with HIV in Bangui, Central African Republic. John Libbey Eurotext. 1998;8:189-192.

6. Mbamba MF. Study of the co-infection of mycoplasmas with the human immunodeficiency virus in a population of Cameroonian women. University doctoral thesis. Yaoundé: University of Yaoundé ; 2013.

7. Faye-Kette H, La Ruche G, Ali-Napo L, et al. Genital mycoplasmas among pregnant women in Côte d' Ivoire, West Africa: prevalence and risk factors. Int JSTD AIDS. 2000;11(9):599-602.

8. Mamadou S, Laouel Kader A, Rabiou S, et al. Prevalence of the HIV infection and five other sexually- transmitted infections among sex workers in Niamey. Niger Bull Soc Pathol Exot. 2006;1(99):19-22.

9. Levine CW, Pope V, Bhoomkar A, et al. Increase in endocervical CD4 lymphocytes among women with non ulcerative sexually transmitted diseases. J Inf Dis. 1998:167-174.

10. Njunda AL, Nsagha DS, Assob JC, et al. Genital mycoplasmas in women attending the Yaoundé university teaching hospital, Cameroon. J Public Health Afr. 2011;2(1):e16.

11. Lortholary O, Duvivier C. Inflammatory and infectious processes: Teaching unit 2.5. Elsevier Health Sciences; 2013. 260 p.

12. Vasanthakumari R. Textbook of microbiology. BI Publications Pvt Ltd; 2007.

13. Pebret F. Infectious diseases: all pathologies from the official medical or paramedical study programs. Hours of France ; 2003.

14. Pathophysiological mechanisms of bacteremia. Medical microbiology. Elsevier-masson; 2007.

15. Barre Senoussi F. Basic virology of HIV infection in Gerard P-M. In: Katlama Ch, Pialoux G, editors. VIH ed. Paris: Dion Editeur; 2003.

16. Kreans B, Gallagher H. Predicting the prevalence of chronic kidney disease in the English population: a cross-sectional study. BMC Nephrol. $2013 ; 14: 49$

17. Clavel F, Guetard D, Brun-Vezinet F, et al. Isolation of a new human retrovirus from West African patients with AIDS. Science. 1986;233:343-346.

18. Launay O, Joly V, Yeny P. Place of non-nucleoside reverse transcription inhibitors in the antiretroviral therapeutic strategy: infection letter. 1998:6-8.

19. Lannes D, Mendoza-buffet G. Immunosuppression in HIV infection and immunosuppressive therapies. 2011

20. Cu-uvin S, Hogan J, Caliendo A, et al. Association between bacterial vaginosis and expression of human immunodeficiency virus type 1 RNA in the female genital tract. Clin Infect Dis. 2001;33(6):894-896. 